\title{
Coronavirus: una amplia familia de virus no tan nueva
}

\section{Coronavirus: A viruses wide family not so new}

\author{
Carlos Castro Cavadía' \\ Por la notabilidad y coyuntura temática, se publica esta carta enviada al editor. \\ Quien reconoce en la misma la rigurosidad y seriedad en la escritura del autor, ante la \\ situación inédita que está viviendo la humanidad en la declaratoria de la pandemia por \\ a presencia de la Covid-19 en muchos paises del mundo.
}

\begin{abstract}
Empiezo esta comunicación, invitándolos a una breve reflexión acerca del manejo de la información que se recibe y difunde en estos tiempos de pandemia. Ante la emergencia sanitaria que se vive en el mundo por la expansión de la Covid-19, uno de los aspectos que se propaga rápidamente y es igual de peligroso que el propio virus son las noticias falsas y la desinformación, lo cual ha generado un fenómeno que la Organización Mundial de la Salud (OMS) nombró como infodemia. Otro fenómeno que acompaña a la pandemia de la covid-19 es la infoxicación. Es decir, la sobrecarga informativa. Por ejemplo, realizando una búsqueda el dia 6 de mayo de 2020 en google empleando las palabras coronavirus covid-19, el buscador nos arroja 2,800,000,000 de resultados asociados a la búsqueda, lo cual representa un cúmulo de información y ello se magnifica en importancia si se tiene en cuenta lo relativamente nueva que es la pandemia.
\end{abstract}

Y el panorama no es muy diferente cuando se limita la búsqueda a una de las bases de da-

PhD(c) en Ciencias Básicas Biomédicas. MSc en Microbiología. Bacteriólogo, Docente Universidad de Córdoba. Correspondencia: carloscastro@correo.unicordoba.edu.co tos más importantes en las ciencias biomédicas (PubMed). Allí se encuentran 5,135 resultados asociados con la busqueda de las palabras coronavirus Covid-19.

Ahora si, se abordaran los agentes virales que inspiraron el título de esta comunicación: los Coronavirus, una extensa familia de virus RNA de importancia médica y veterinaria, los cuales se caracterizan por ser esféricos, envueltos y con proyecciones prominentes en sus superficie, a las que se conocen como espículas (1) y cuya apariencia bajo el microscopio electrónico se asemeja a una corona, pero no a las que portaban los monarcas sobre sus regias cabezas, sino a la corona solar, es decir al aura de plasma que rodea a nuestro astro rey, el sol.

El término "coronavirus" aparece mencionado en un artículo de la revista Nature, publicado en el número del 16 de Noviembre de 1968 (2).

Contando con el causante de la actual pandemia (SARS-CoV-2) de covid-19, la ciencia ha identificado y aislado siete coronavirus circulando entre los humanos (3). Todos saltaron 
desde animales en poco más de un siglo, pero los más patogénicos emergieron en los últimos 20 años. En la mayoría de ellos se conocen sus hospederos naturales e intermedios, siendo los murciélagos los reservorios naturales más importantes identificados hasta ahora. Aún hay miles de coronavirus en la naturaleza, la inmensa mayoría por describir. Los últimos fueron publicados apenas hace unos días (4). Todos eran nuevos para la ciencia $y$, aunque sus descubridores no creen que supongan una amenaza, aún tienen que estudiarlos para determinar el riesgo de que puedan saltar a los

\section{REFERENCIAS}

1. Brian DA, Baric R. Coronavirus Genome Structureand Replication.CurrTopMicrobiol Immunol. 2005 Feb 1;287:1-30. doi: https://doi.org/10.1007/3-540-26765-4_1

2. Virology: Coronaviruses. Nature [Internet]. 1968;220(5168):650. Available from: https://doi.org/10.1038/220650b0

3. Cui J, Li F, Shi ZL. Origin and evolution of pathogenic coronaviruses. Nature Reviews Microbiology. 2019. doi: https:// humanos. Y un estudio de 2017 estimó que, solo entre los murciélagos, había más de 3.200 coronavirus (5).

Mediante esta comunicación deseo remarcar que los coronavirus y muchos otros virus conviven desde hace muchos años entre animales silvestres y se han adaptado a diferentes hospederos, incluidos el hombre y el principal peligro al que nos enfrentamos, es considerar al nuevo coronavirus como un fenómeno aislado, sin historia, sin contexto social, económico o cultural.

doi.org/10.1038/s41579-018-0118-9

4. Valitutto MT, Aung O, Tun KYN, Vodzak ME, Zimmerman D, Yu JH, et al. Detection of novel coronaviruses in bats in Myanmar. PLoS One. 2020. doi: https:// doi.org/10.1371/journal.pone.0230802

5. Anthony SJ, Johnson CK, Greig DJ, Kramer S, Che X, et al. Global patterns in coronavirus diversity. Virus Evol. 2017. doi: $\quad$ https://doi.org/10.1093/ve/vex012 